\title{
Da performance à gravação: pressupostos do debate sobre a estética do rock
}

\section{Jorge Cardoso Filho}

\section{Resumo}

A partir da revisão de teses representativas sobre uma estética particular do Rock, o artigo problematiza os pressupostos sobre performance e/ou gravação como objetos estéticos e sugere deslocar o debate para 0 entendimento sobre os elementos chamados em causa na experiência com Rock, em diferentes contextos. Como conclusão, apresenta a possibilidade de identificação de padrões poéticos predominantes na experiência musical que podem ser objetos de estudo da comunicação.

\section{Palavras-chave}

Rock. Estética. Comunicação.

Jorge Cardoso Filho | jcunha@fafich.ufmg.br Jornalista. Mestre em Comunicação e Cultura Contemporâneas - UFBA e doutorando em Comunicação - UFMG. Professor do Departamento de Filosofia e Ciências Humanas - UESB, Vitória da Conquista.

\section{Rock enquanto objeto da Estética}

Bruce Baugh, no ensaio intitulado Prolegomena

to Any Aesthetics of Rock Music, publicado em 1993 no The Journal of Aesthetics and Art

Criticism, foi quem iniciou os questionamentos sobre a necessidade de pensar a crítica estética do Rock associada às características expressivas particulares dessa música - e não a partir de características importadas de outras tradições musicais. Sua ambição era apresentar os elementos que deveriam ser levados em consideração para avaliar a beleza musical do Rock, diferenciado-o da música erudita, que 0 autor afirma estar eminentemente preocupada com aspectos formais.

Sua discussão sobre os parâmetros para a construção de uma "estética do Rock" destaca três elementos principais: 0 ritmo, que inspira o corpo a dançar; a performance, que concede ao formato "um padrão que relaciona totalidade do sentimento investido, com as nuanças do sentimento exprimido" ; e a altura do som, que é utilizada como um veículo de expressão. Grosso modo, pode-se dizer que Baugh considera que, 
como o Rock está vinculado a outra tradição musical, não seria possível usar a estética tradicional para avaliar sua beleza.

A música do rock compreende um conjunto de práticas e uma história muito diferente daquelas da tradição europeia da sala de concerto na qual a estética tradicional está baseada. Assim sendo, qualquer tentativa de avaliar ou compreender a música rock usando a estética da música tradicional está condenada a resultar num mal-entendido (BAUGH, 1993, p. 23, tradução nossa).

0 autor infere a necessidade de compreender que a proposta do Rock está distante da fruição abstrata das formas (e de uma estética formalista) e mais próxima do efeito que a matéria musical produz no ouvinte (e de uma estética da expressividade, portanto). Por matéria musical, Baugh compreende elementos amplos, que não permitem descrição ou identificação rigorosa, mas que se diferenciam nitidamente dos aspectos formais. Sua proposição é que a performance é o principal objeto estético do Rock, em contraposição à partitura, que ele afirma ser o objeto estético da música clássica.

A proposta de Baugh ecoou tanto no universo da crítica acadêmica quanto no âmbito da comunidade de ouvintes, afinal a partir de sua proposta era possível declarar que 0 Rock tinha seus próprios padrões de beleza, fator de suma importância para a crítica especializada. Muitos se engajaram no debate de modo a contribuir ou apresentar limites às sugestões do autor. Um dos primeiros foi James Young, que estabeleceu um debate com Baugh na edição subsequente do mesmo periódico onde Prolegomena havia sido publicado.

Para Young, os elementos destacados por Baugh como característicos da Estética do Rock (ritmo, performance e altura do som) seriam os mesmos elementos levados em consideração em outros gêneros musicais, inclusive na música erudita - que Baugh chamou, equivocadamente, de música clássica. Young sumariza que "cada um dos padrões de excelência que Baugh identifica na performance de Rock se aplicam de igual maneira para as performances de música erudita" (YOUNG, 1995, p. 81, tradução nossa).

A falta de uma definição do que Baugh entende por Rock e música clássica é o outro ponto que Young ataca. Como não descreve ou mapeia a tradição que ele diz originar o Rock, Baugh teria construído uma tese frágil, que dá conta apenas dos padrões de alguns grupos de Rock (não é verdade que todos os grupos possuem a performance como elemento privilegiado, há aqueles que são orientados especificamente para a gravação). Também não seria possível afirmar que a música erudita está preocupada, sobretudo com aspectos formais (dramas musicais de Richard Wagner, como Die Walküre ou Rienzi pareciam mesmo apelar para dimensões materiais da música).

Argumentos bastante convincentes também foram construídos por Stephen Davies, que revisou as proposições explicitadas no debate entre Baugh e Young para mostrar que o Rock 
está inserido na mesma tradição tonal que a música erudita e, por isso, deverá ser avaliado segundo os mesmos padrões estéticos que qualquer música tonal (DAVIES, 1999). Um dos principais problemas, segundo Davies, foi que Baugh fez uma distinção muito radical entre aspectos formais e aspectos expressivos, que acabou por comprometer a validade de suas proposições.

0 fato de haver privilégio a aspectos "nãoformais" no Rock, como o apelo para a dimensão somática e a resposta fisiológica que a música impõe ao ouvinte, não significa dizer que esse apelo seja inexistente na música erudita (dançava-se ao ouvir valsas e minuetos de Haydn, Mozart etc.). Do mesmo modo, embora as técnicas para tocar música erudita e rock sejam diferentes, isso não é consequência de uma maior naturalidade no aprendizado das técnicas musicais do Rock, que são tão convencionais quanto as da música erudita.

Para Davies, a melhor forma de provar que as técnicas são diferentes é mostrar os detalhes sonoros aos quais essas músicas aspiram. 0 Rock prefere timbres sujos e bent pitches, e a música erudita não. De maneira provocativa e bastante convincente, 0 autor conclui que, caso a ideia proposta por Baugh de uma "Estética do Rock" estivesse correta, seria necessário formular uma estética para cada subgênero do Rock e da própria música erudita, consequência que não seria muito razoável.
Um rumo diferente do que fora proposto por Baugh, mas também defendendo uma Estética do Rock, foi tomado por Theodore Gracyk em Rhythm and Noise: an aesthetics of Rock. Ao contrário do que propunha Baugh, não seria a preocupação com a performance dos sons e uma estética da expressividade que caracterizaria a peculiaridade do Rock. Gracyk, atento ao processo de emergência do Rock enquanto objeto cultural, pensa que é a gravação o principal objeto estético.

A maior característica distintiva do Rock em relação à música popular deve estar na dimensão da ontologia, no que é uma obra musical no Rock, em oposição ao que é, por exemplo, ao que é uma obra musical no Jazz, Country ou Folk. Rock é uma tradição de música popular cuja criação e disseminação está centrada na tecnologia de gravação (GRACYK, 1996, p. 1, tradução nossa).

Assim, 0 autor busca legitimar sua posição mediante 0 exame do modo como o Rock emergiu genealogicamente e a partir dos estudos de autores que enxergam a peculiaridade da música que surgiu na década de 50. "Rock n' Roll diferiu de formas anteriores de música em que a gravação foi 0 medium inicial porque nele a tecnologia surge como um elemento mesmo da música" (GAROFALO, 1992 apud GRACYK, 1996, p. 37, tradução nossa) e também:

Apesar do Jazz e de outros tipos de música folk existirem em gravações, eles não são originários desse medium. Na sua maior parte, elas se originaram e desenvolveram através de performances ao vivo. 0 Rock, me parece, fez exatamente 0 oposto. As gravações foram 
medium inicial da música (BELZ, 1972 apud GRACYK, 1996, p. 37, tradução nossa).

Como extrai o objeto central da crítica estética do Rock de um contexto mais preciso (a década de 50) e delimitado que Baugh, tomando cuidado em mostrar elementos técnicos, culturais e mesmo econômicos que influenciaram a emergência do Rock, 0 argumento de Gracyk é mais forte que a proposição de tomar a performance dos sons como principal elemento a ser avaliado. Parecendo responder à crítica de Young sobre a forma vaga como Baugh caracterizou o Rock, Gracyk acabou por estabelecer um contorno mais nítido para a tese da Estética do Rock e ofereceu novos caminhos para serem seguidos.

Isso não significa, contudo, que a performance ao vivo perca todo o seu valor. Ela também pode ser, ter sido ou vir a ser o principal elemento de avaliação do valor musical no Rock. Isso depende de configurações sociais e culturais, bem como da apropriação musical em um contexto passado, presente ou ainda futuro. Tendo observado essas configurações, Gracyk fundamentou sua proposta num padrão de experiência reconhecível e identificável. Segundo ele, o próprio Elvis Presley precisou ter dois discos gravados antes de aprender a performar ao vivo para o público (GRACYK, 1996).

Uma das principais consequências da proposição de Gracyk é a negação do princípio "realista" na experiência com o Rock. Ou seja, como o objeto estético é a gravação, não há necessidade de representar nela 0 evento que ocorre ao vivo. Na verdade, será a gravação que informará/originará as apresentações ao vivo. "A gravação em estúdio não é somente o registro de uma sonoridade anterior e igual (a da performance ao vivo); mas sim um processo de criação musical per se, com sua própria estética, valores e referências" (SÁ, 2006, p. 08).

Assim, como elemento decisivo de constituição do Rock, a prática de gravação é circunscrita como objeto estético privilegiado de estudo, uma vez que são esses objetos que exploraram os pontos das configurações culturais (práticas musicais, técnicas de produção, distribuição e consumo, as expectativas dos ouvintes etc.) de modo a suscitar o engajamento dos ouvintes numa situação comunicacional que depende de aspectos midiáticos. Pensado nesse sentido, 0 Rock é uma expressão da reprodução midiatizada e só posteriormente da co-presença.

Raramente, entretanto, esse processo produtivo é apresentado ao público, de modo que prevalece um apagamento da gravação (assim como houve a tentativa de apagar a câmera, no cinema de um período). Poucas fotos sobre história do Rock apresentam os músicos no estúdio. As imagens que documentam a experiência com o Rock 0 fazem a partir de fotos de shows e performances, totens que contribuem para o sentimento de partilha entre os fãs. De qualquer forma, a primeira consequência da proposição de Gracyk encaminha a atenção do estudioso para pensar 
o Rock como uma expressão que é fruto das técnicas de reprodutibilidade.

0 segundo aspecto interessante na reflexão de Gracyk é identificação de duas estratégias básicas de romantização do Rock. A primeira dessas estratégias, que ele identifica no pensamento de Camille Paglia, vai criticar características do Rock, tais como: perda da autenticidade, perda da importância da performance ao vivo e a exploração pelos empresários. Trata-se de uma romantização subjetivista, na medida em que pensa o Rock como a expressão de uma singularidade (lirismo) que se perdeu após a exploração capitalista. A solução, para ela, seria 0 retorno do Rock às universidades e a um sistema de mecenato artístico que recupere sua autonomia; "a música rock não deve ser abandonada às leis darwinistas do mercado... para o rock avançar como uma forma de arte tem de ser dada aos nossos músicos a oportunidade para o desenvolvimento espiritual" (PAGLIA, 1992 apud GRACYK, 1996, p. 194, tradução nossa).

A segunda estratégia de romantização é identificada por Gracyk nas formulações de Cohn e Belz, que sugerem pensar o Rock exclusivamente como a expressão da voz de um grupo, um grupo que tradicionalmente foi marginalizado dos sistemas de representação das grandes artes. Neste sentido, o Rock estaria mais próximo da tradição da Folk Art.

Para Cohn e Belz, o declínio do Rock teve início quando os Beatles e outros se voltaram para a auto-expressão e a experimentação musical em si mesma. Nesse sentido, 0 Rock perdeu sua identidade especial quando os músicos começaram a falar por si mesmos ao invés de falar pelas suas audiências (GRACYK, 1996, p. 188, tradução nossa).

Gracyk conclui que é preciso assumir a tradição de consumo midiático do Rock a fim de evitar romantizações excessivas sobre 0 potencial de resistência cultural ou força dionisíaca do gênero musical. Mas não nega que, como programa, 0 romantismo ressaltou valores importantes para 0 Rock, sobretudo valores que reagiram aos objetos clássicos da arte, ao intelectualismo e às rígidas estruturas artísticas. Como arremate, lança um olhar descrente sobre a validade da Estética tradicional para o estudo do Rock ao afirmar que ela, normalmente, negligencia o contexto histórico e social da arte ou pensa as obras de arte como corporificações do imutável, universal e transcendental.

Esses pontos, entretanto, merecem uma discussão mais cuidadosa. Tanto pela necessidade de entender um pouco mais a tradição musical que vem sendo discutida (tema), quanto pela posição concedida à reflexão estética na formulação das propostas (forma).

\section{Rock enquanto tradição musical}

Stephen Davies e James Young, ao insistirem em uma espécie de continuidade entre música erudita e Rock (ambas espécies de música tonal), parecem mesmo desconsiderar 0 contexto histórico e social a partir do qual o Rock emergiu. 
Isso se distingue nos mais variados aspectos da emergência da música erudita, atitude identificada como problemática tanto por Baugh quanto Gracyk. 0 problema reside no fato de supor que, por estarem ligados ao mesmo sistema musical, Rock e música erudita teriam um mesmo percurso de apropriação e escuta. A objeção imediata é que a filiação a um sistema musical não impossibilita que elementos musicais sejam diferentemente organizados dentro desse sistema - um elemento pode ser extremamente valorizado em uma tradição e totalmente dispensável em outra.

Enxergar o Rock enquanto objeto da estética não significa apenas aplicar noções estéticas para 0 estudo do Rock, mas sim entender as configurações sociais e musicais que permitem que Rock emerja como gênero musical e cultura. Martín-Barbero (1991) oferece, a partir do estudo sobre o uso social dos meios, uma chave paradigmática de extremo valor para entender processos dessa natureza, sobretudo com a proposição do seu "mapa noturno das mediações". Grosso modo, o teórico colombiano apresenta uma espécie de mapa composto por dois eixos (um sincrônico e outro diacrônico) que são tensionados por lógicas de produção e competências de recepção no primeiro eixo e matrizes culturais e formatos industriais no segundo eixo. Entre esses pontos há variadas formas de mediação: institucionalidades, socialidades, tecnicidades e ritualidades.
Observar 0 contexto a partir do qual o Rock emergiu, a partir do mapa proposto por MartínBarbero, permite identificar os Estados Unidos da América da década de 50, ainda com regimes segregacionistas entre brancos e negros. Trata-se de uma música que tinha sua raiz no Blues e no Rhythm Blues e dialogava com a música country e com o Folk, que se desenvolvia ao mesmo tempo em que a cultura agrária era substituída por uma cultura jovem e urbana, que celebrava avanços tecnológicos como a televisão e via 0 início do baby boom (alta taxa de natalidade nos países desenvolvidos).

É uma música que nasce no período pós-guerra, que é gravada em pequenos estúdios e distribuída em suportes de acetato (vinil) em formato EP (extended play) por (ainda) pequenos selos especializados - que mais tarde consolidariam a indústria fonográfica. Algumas figuras lendárias do Rock nesse contexto eram Chuck Berry, Elvis Presley, Buddy Holly, Jerry Lee Lewis, Johnny Cash, Fats Domino, Little Richards, Bill Halley and the Comets, entre outras. No cinema, filmes como Blackboard Jungle (1955) contribuíram significativamente para a popularização do gênero musical ao visibilizar a rebeldia como um aspecto da cultura juvenil recém-formada.

0 Rock foi tomado como sintoma de um novo tipo de experiência com a música e, desde 0 seu surgimento, alvo de críticas. Uma das mais famosas é a do teórico americano Allan Bloom, que em The closing of the American 
mind narra o fracasso da cultura americana em cultivar valores interessantes para os jovens e usa como evidência, entre outras coisas, 0 enorme sucesso do Rock entre a juventude universitária ${ }^{1}$. 0 subtítulo do livro de Bloom, How higher education has failed Democracy and impoverished the souls of today's students (Como a educação superior minou a Democracia e empobreceu a alma dos estudantes de hoje) indica que 0 cultivo do Rock seria apenas 0 sintoma de um mal maior, o enfraquecimento do projeto democrático nacional americano. Para ele, a juventude americana teria trocado os livros e a música erudita pelos discos e pelo Rock, no qual "só há um apelo, o apelo bárbaro ao desejo sexual - não ao amor, não Eros, mas desejo sexual subdesenvolvido e inculto" (BLOOM, 1987, p. 73, tradução nossa).

No que diz respeito aos elementos musicais, 0 Rock se caracteriza pela música eletrificada, que incorpora os meios eletroacústicos na sua dimensão poética - tanto no âmbito da performance ao vivo, quanto no processo das gravações - e conforma um hábito de escuta em consonância com os usos desses meios. Não importa se a referência é a apresentação ao vivo de uma banda de Rock ou à escuta de uma música gravada e reproduzida posteriormente, os elementos eletroacústicos (como a guitarra elétrica e, posteriormente, os sintetizadores) são fundamentais.
Certamente, microfone, amplificadores e alto-falantes são importantes para praticamente todas as músicas gravadas: clássicas, folk, jazz ou popular. Entretanto, é somente na música pop e no rock que essas tecnologias podem ser consideradas como verdadeiramente essenciais nos processos tanto de expressão quanto de experiência musical (THÉBERGE, 2001, p. 08, tradução nossa).

No âmbito dos elementos da linguagem musical, Arnold Shaw afirma que o Rock privilegia uma batida 4/4 e o padrão de 12 compassos do Blues (enquanto a música Pop teria se desenvolvido a partir do padrão de oito ou 16 compassos). Também, segundo o autor, é ritmicamente modelado pelos parâmetros do Boogie-Woogie, tende a privilegiar os aspectos modais em relação aos diatônicos e tende a enfatizar a energia e a sobrecarga sensória, mediante o uso de feedback, reverberação e pedais wah-wah (SHAW, 1982).

Tais elementos permitem entender, de forma geral, os aspectos ideológicos, culturais e técnicos que possibilitaram/constrangeram o Rock na década de 50, ou seja, eles descrevem os pontos no mapa das mediações que configuravam naquele contexto a sua emergência. A dificuldade encontrada pelos pesquisadores em oferecer uma definição precisa sobre o que é 0 Rock, como Robins (2008), Friedlander (2004) e o próprio Gracyk (1996), indica que o gênero se reconstrói de forma dinâmica e que o papel do pesquisador é 0 de reconstituir, a partir dos vestígios deixados 
no espaço de experiências, a organização do mapa das mediações que configurou aquele período.

Assim, é de maneira bastante lúcida que Jeder Janotti Júnior propõe encarar o Rock como um mapa reconstruído constantemente devido às forças de mercado, mudanças na sensibilidade e na espacialidade (JANOTTI JÚNIOR, 2003). Para ele, 0 estudo dos produtos do Rock nunca deve estar separado do contexto no qual tais objetos fazem sentido, pois os valores, gostos e afetos estão presentes tanto na poética de confecção quanto no processo de fruição. Também Keir Keightly, ao revisitar "capítulos" da história do Rock demonstra como o gênero se transforma numa verdadeira cultura, sofrendo mutações frequentes (KEIGHTLY, 2001). Finalmente, há o trabalho de Andrew Kania, que sugere que a dimensão ontológica do Rock reside nas tracks (construções gravadas) que manifestariam canções (performances) (KANIA, 2006). 0 autor recupera a proposição feita por Gracyk sobre a gravação como objeto estético e contrasta com novas teses de Stephen Davies (2001) em Musical works and performances, a fim de criar uma alternativa para a oposição perfomance $X$ gravação, pressuposto tão recorrente no debate.

Partindo do mapa das mediações, a investigação sobre qual é o objeto para a crítica estética do Rock ganha contornos mais precisos e permite falar sobre formas de organização da complexa rede de mediações que perpassa a experiência com a música. Uma das mais reconhecidas e mais utilizadas dessas organizações por músicos, fãs e críticos são os gêneros musicais, também considerados como organizadores/reveladores dos elementos dinâmicos da experiência musical.

Franco Fabbri apresenta algumas regras que atuam na conformação do gênero, como as regras técnicas formais, as regras semióticas, as regras comportamentais, sociais e ideológicas e as regras jurídicas e econômicas (FABBRI, 1981). Felipe Trotta, em uma concepção bastante similar à de Fabbri, aponta que os gêneros musicais instauram "ambientes afetivos, estéticos e sociais" a partir dos quais as relações com a música serão reguladas (TROTTA, 2008). Simon Frith considera que os ouvintes, sejam eles fãs, críticos ou ouvintes ocasionais, julgam a música que ouvem a partir das características dos gêneros, na relação que se estabelece entre 0 que fora construído como expectativa e que se configura na música (FRITH, 1996).

As argumentações de cada um desses autores revelam concepções sobre como determinada música deveria soar, quais tipos de características ela deveria ter, ou seja, revelam um conjunto de valores partilhados tanto ética, quanto cultural e tecnicamente que são resultado das mediações que atuam na configuração do gênero musical, num contexto determinado. Segundo Robert Walser, os gêneros musicais

Funcionam como horizontes de expectativas para leitores (ou ouvintes) e como modelos de composição para autores (ou músicos). Mais importante, Todorov argumenta que gêneros 
existem porque as sociedades coletivamente escolhem e codificam os atos que correspondem às suas ideologias. 0 discurso de uma sociedade depende de seus materiais brutos linguísticos (ou musicais) e de ideologias circunscritas historicamente. Discursos são formados, mantidos e transformados pelo diálogo; falantes aprendem com e respondem a outros, os significados das reiterações nunca são permanentemente fixos, não podem ser encontrados num dicionário (WALSER, 1993, p. 29, tradução nossa).

Como não são permanentemente fixos, os gêneros se reinventam e resistem a definições dogmáticas que os pensam como sistemas de força determinante, que anulam as possibilidades de fuga, oscilação e contribuição singular das experiências musicais, fundamentalmente da experiência estética. Como acertadamente pontua Martin Seel, a apreensão da singularidade estética do fenômeno só se dá a partir de um bom conhecimento do geral com o qual a experiência se relaciona (SEEL, 2005), generalidade que se apresenta também na organização dos gêneros musicais. Nesse sentido, a definição de um gênero musical consiste na explicação sobre a conformação do mapa das mediações em um determinado contexto temporal e sobre os modos como essa conjuntura fez prevalecer certo tipo de experiência com a música.

A emergência de uma prática cultural ou mais especificamente uma tradição musical não ocorre de maneira causal, mas através de uma reorganização das mediações que atuam na experiência com a música que faz predominar determinados programas de produção e recepção. 0 crescimento de reflexões e propostas interessadas em averiguar a existência de uma estética específica para o Rock ocorre porque os pesquisadores constatam que novas configurações do mapa das mediações requisitam novas formas de apreensão do estético ${ }^{2}$. Esse movimento repercute entre filósofos, sociólogos, musicólogos e mesmo nos estudiosos da literatura.

Eu me recuso a prognosticar, como alguns fizeram, a morte da literatura. Desejo que ela perdure; mas 0 que não pode deixar de mudar é 0 tipo de mediação com o poético. Citaria como significativa a esse respeito a invasão de nosso universo cultural, há uns 30 anos, por formas de arte das quais o rock me parece o emblema. Apesar da mediocridade textual (mas não é esta a questão) do canto na música rock, 0 que testemunhamos aqui é uma irreversível "corporização" do prazer poético, exigindo (depois de séculos de escrita) o uso de um meio menos duro, mais manifestamente biológico (ZUMTHOR, 2007, p. 70).

Ao tomar a mudança nos "tipos de mediação com o poético", ou seja, das conformações no mapa das mediações, como indício da necessidade de pensar numa nova forma de lidar com o prazer poético, Zumthor constata a necessidade de tomar uma forma que seja "mais manifestamente biológica" e que a teoria Estética tradicional

Esse debate foi feito em Cardoso Filho (2009) a partir da discussão com as posições de Richard Shusterman e de Bruce Baugh, que tendem a caracterizar o Rock e o Funk como gêneros inteiramente novos, manifestações de uma experiência pós-moderna e que, portanto, não poderiam ser estudados por uma disciplina forjada na concepção do projeto filosófico moderno, como a Estética. Pelos motivos já destacados, entretanto, desconfiamos de tal posicionamento. 
não havia privilegiado. Não há morte de um tipo de experiência (a literária), mas é necessário atentar para o nascimento de outros tipos de experiência que emergem com o que ele chama de "corporização" do prazer.

Como leitor crítico da tradição da Estética da Recepção, Zumthor foi além da proposta de pensar a experiência estética como uma modalidade da hermenêutica literária e trouxe a corporalidade condicionante das experiências com objetos estéticos para o centro da reflexão, de modo a dar conta dessa nova configuração, da qual o Rock é a expressão emblemática. Uma conduta específica se desenvolve em sintonia com esse padrão de experiência, e a partir do estudo dessa conduta (do que é chamado em causa nela) é possível estabelecer qual programa de produção e recepção é predominante.

Consequentemente, determinar 0 objeto de avaliação estética do Rock só é uma atitude legitima quando há respeito aos pontos do mapa das mediações configurados naquele padrão de experiência, caso contrário a performance, gravação ou track aparecem como pressupostos duvidosos de um discurso que pretende determinar a essência ontológica e imutável do Rock e, a partir dela, extrair seu objeto de avaliação estética. Curiosamente, os mesmos autores que acusam a Estética de ser um discurso sobre o imutável e universal das obras de arte acabam construindo teses sobre a essência do Rock e desconsideram as importantes transformações em jogo na experiência com as singularidades. Felizmente, a Estética tem mais a dizer sobre a experiência com o singular.

\section{A virada da Estética Filosófica}

É justamente pelo modo heterogêneo como cada um dos autores que propuseram/questionaram a Estética do Rock caracterizam a Estética como um todo - aquela disciplina filosófica surgida em meados do século XVIII e que pretende refletir sobre o belo e o conhecimento sensório - que é possível responder algumas velhas perguntas e apresentar novas questões. Seja por falta de pesquisa em outras tradições filosóficas ou estratégia de construção argumentativa, Baugh e Gracyk (apesar deste ser filósofo) fizeram um retrato caricatural da Estética, de modo que a disciplina acabaria tendo pouca capacidade de explicação dos fenômenos.

Baugh, por exemplo, reduz a teoria Estética a uma estética formalista e toma como representantes dessa tradição nomes como Edward Hanslick e Immanuel Kant (BAUGH, 1993). Curiosamente, ele desconsidera toda a reflexão sobre 0 caráter subjetivo e ao mesmo tempo universal do gosto na obra do filósofo alemão - que impossibilitaria concluir que a estética pensada por Kant tem inspiração formalista.

Gracyk vai dar duas afirmações questionáveis sobre a Estética: a primeira seria que ela aborda seus temas pressupondo que a arte é uma esfera autônoma e que critérios imutáveis devem ser 
usados para avaliá-la; a segunda que, como a Estética opõe essa arte ao comércio (ou melhor, à indústria cultural), a configuração do mapa das mediações que faz o Rock emergir impede este de ser tomado como objeto de reflexão estética, afinal, não se trataria de arte, mas de um fenômeno vinculado às indústrias de entretenimento. Embora seja possível afirmar que muitos filósofos tomaram os caminhos criticados por Gracyk, é equivocado pensar que não houve resistência a esses movimentos no campo filosófico (a estética pragmatista norte-americana e a Estética da Recepção, na Alemanha, são bons exemplos).

De forma geral, pode-se dizer que uma preocupação com os aspectos relacionados à experiência, não à arte, conduziu a reflexão desses autores para um reposicionamento da Estética no campo da filosofia. Tratava-se de perceber os componentes estéticos presentes nas variadas experiências humanas, e não apenas em objetos específicos, para distinguir essas experiências a partir de graus, posicionamento que concede uma envergadura compreensiva muito maior à Estética,

Obviamente, essa amplitude também foi criticada. A partir dos anos sessenta, filósofos da tradição analítica formularam críticas fortes à ideia de que seria possível distinguir um tipo de experiência específica no conjunto das diversas outras existentes no mundo e que tal diferença residia na natureza estética daquela em relação a estas. Dickie (1965) propôs, inclusive, o abandono do conceito de experiência estética em favor do questionamento acerca dos constrangimentos sociais e culturais que nos possibilitam reconhecer os objetos de arte enquanto tais, formulando assim a sua teoria institucional da arte. Desse modo, a teoria Estética voltaria a estar restringida pelas condições sociais de fruição e determinação da arte.

0 debate desenvolveu-se com argumentos interessantes em ambos os lados e, reconhecendo que ampliações generalizantes ou reduções caricaturais foram atitudes comuns nas reflexões contemporâneas sobre a Estética, Martin Seel busca recolocar a disciplina em uma posição de destaque do pensamento filosófico ao construir sua tese sobre uma estética do aparecer. Para 0 autor, estéticos são aqueles encontros nos quais há apreensão dos aspectos sensórios (imagéticos, sonoros ou táteis) de uma forma mais ou menos diferente da conceitualmente determinada (SEEL, 2005). Tal fenômeno pode ocorrer tanto com objetos do cotidiano quanto com os objetos da arte moderna. Nesse sentido, ao mesmo tempo em que reconhece a força contextual e histórica da tradição que abriga aquele objeto, sua teoria estética está aberta para incorporar as singularidades de cada encontro.

Pode-se dizer que para apreender a singularidade da experiência estética e ser capaz de descrever padrões instituídos (que conformaram 0 hábito de percepção) é necessário respeitar os 
pontos do mapa das mediações configurados naquele contexto. Um ponto de partida aberto o suficiente, que possibilite incorporar as diferentes mediações que atuam na experiência com o Rock em seus respectivos contextos, é condição fundamental, caso contrário uma tese demasiadamente normativa sobre a expressão musical é construída e se perde de vista as nuances que se desenvolvem no processo dinâmico de transformação do gênero.

0 musicólogo Ralf von Appen (2007), que aplica à música o proposição estética de Seel, interpreta a partir de questionários empíricos e de resenhas publicadas pelos ouvintes no site da amazon. $d e-o$ s valores usados pelos ouvintes para julgar o Rock. Ao identificar quais aspectos musicais são valorizados, Appen tem acesso aos elementos da experiência destacados pelos ouvintes como mais ou menos importantes e, desse modo, pode apreender os novos padrões a partir dos quais 0 Rock é experienciado.

Isso significa que a necessidade de construção de uma teoria estética específica para o Rock só pode estar fundamentada no tipo de experiência que está em jogo. Se a conformação do mapa das mediações é totalmente nova a ponto da descrição e da apreensão serem impossíveis a partir dos parâmetros já construídos, torna-se fundamental reconhecer a original proposição de Baugh e Gracyk ao reivindicarem a construção da Estética do Rock - seja ela amparada na performance ou na gravação. Contudo, a construção de uma Estética do Rock é necessária somente se os elementos chamados em causa na experiência que o ouvinte mantém com Rock sustentarem a necessidade de formulação de uma nova teoria estética.

Se, ao contrário, o que os autores estão a chamar de "Estética do Rock" continue sendo um caso específico de expressão que a Estética pode dar conta, é necessário inquirir sobre os elementos que se reorganizaram no mapa das mediações e promoveram "inovações" ou "rupturas" na tradição anterior, de modo que a investigação se ocupe das reorganizações no mapa das mediações da experiência com o Rock e os padrões instaurados por essas novas configurações. Tanto performance quanto gravação podem ter sido elementos fundamentais para a definição do que o Rock era num contexto específico, mas esses fatores simplesmente, como se quis demonstrar, não determinam um valor universal para 0 gênero musical.

A proposição, portanto, é a de uma investigação sobre os diferentes hábitos de escuta do Rock, a partir dos objetos ou fenômenos que marcaram diversificados contextos, a fim de compreender como as configurações do mapa das mediações contribuíram para a conformação da experiência e para a instituição não de uma "Estética do Rock", mas de programas poéticos distintos. Dessa forma, o debate é recolocado na dimensão da experiência com os objetos em seus respectivos contextos e evita partir do 
pressuposto que determinada característica é, por si mesma, distintiva da tradição à qual 0 Rock se vincula.

\section{Referências}

APPEN, Ralf von. On the aesthetics of popular music. Music therapy today, Witten, v. 08, n. 01, p. $05-25,2007$.

BAUGH, Bruce. Prolegomena to any aesthetics of rock music. The journal of aesthetics and art criticism, Filadélfia, v. 51, n. 01, p. 23 - 29, 1993. Music for the young at heart. The journal of aesthetics and art criticism, volume 53/01, p. $81-83,1995$.

BL00M, Allan. The closing of the American mind. New York: Simon and Schuster Publishers, 1987.

CARDOSO FILHO, Jorge. As materialidades da canção midiática: contribuições metodológicas.

Revista Fronteiras, São Leopoldo, v. 11, n. 02, p. 80 $-88,2009$.

. A incidência dos conceitos de mediações e experiência no estudo da música popular massiva. In: OLIVEIRA, Ana Cláudia et al. (orgs.). Comunicação e interações. Porto Alegre: Sulina, p. $131-146,2008$.

DAVIES, Stephen. Rock versus Classical Music. The journal of aesthetics and art criticism, Filadélfia, v. 57, n. 02 , p. 193 - 204, 1999.

\section{Musical works and performances:}

a philosophical exploration. New York: Oxford University Press, 2001.

DICKIE, George. Beardsley's Phantom aesthetic experience. The Journal of Philosophy, New York, v. 62, n. 05, p. $129-136,1965$.

FABBRI, Franco. A theory of musical genres: two applications. [S.l.]: [s.n.], 1981. Disponível em: < http://www.francofabbri.net/files/Testi_per_ Studenti/ffabbri81a.pdf>. Acesso em: 31 out. 2009.

FRIEDLANDER, Paul. Rock and roll: uma história social. 3. ed. Rio de Janeiro: Record, 2004.

FRITH, Simon. Performing rites: on the value of popular music. Cambridge: Harvard University Press, 1996.

GRACYK, Theodore. Rhythm and noise: an aesthetics of rock. London: Duke University Press, 1996.

JANOTTI JÚNIOR, Jeder. Aumenta que isso aí é Rock and Roll. Rio de Janeiro: E-papers, 2003.

KANIA, Andrew. Making tracks: the ontology of Rock. The journal of aesthetics and arts criticism, Filadélfia, v. 64, n. 04, p. 401 - 414, 2006.

KEIGHTLEY, Keir. Reconsidering rock. In: FRITH, Simon; STRAW, Will; STREET, John. The Cambridge companion to pop and rock. Edinburg: Cambridge University Press, 2001.

MARTIN-BARBER0, Jesús. Dos meios às mediações. 2 ed. Rio de Janeiro: UFRJ, 2001.

ROBINS, Wayne. A brief history of rock, off the record. New York: Routledge, 2008.

SÁ, Simone. A música na era de suas tecnologias de reprodução. E-Compós, Brasília, v. 06, p. 01-15, 2006.

SEEL, Martin. Aesthetics of appearing. Stanford: Stanford University Press, 2005.

SHAW, Arnold. Dictionary of American pop/rock.

New York: Schirmer Books; London: Collier Mcmillan Publishers, 1982. Tradução nossa.

THÉBERGE, Paul. "Plugged in": technology and popular music. In: FRITH, Simon; STRAW, Will; STREET, John. The Cambridge companion to pop and rock. Edinburg: Cambridge University Press, 2001.

TROTTA, Felipe. Gêneros musicais e sonoridades: construindo uma ferramenta de análise. Revista Ícone, Recife, vol. 10, n. 02, p. 1 - 12, 2008. 
WALSER, Robert. Running with the Devil. New York: Wesleyan University Press, 1993.

YOUNG, James. Between rock and a harp place. The journal of aesthetics and art criticism, Filadélfia, v. 53, n. 01, p. $78-81,1995$.

ZUMTHOR, Paul. Performance, recepção e leitura. São Paulo: Cosac Naify, 2007. 
From performance to recording: assumptions of the Rock Aesthetics debate

\section{Abstract}

Reviewing representative theories about Rock's particular aesthetic, the article discusses assumptions that think that performances and/ or recordings are aesthetic objects and it suggests moving the debate to the understanding of the role of each of the elements on Rock s experience in different contexts. As conclusion, it presents the possibility of identifying prevalent poetic patterns in musical experience that can be objects of study of Communication.

\section{Keywords}

Rock. Aesthetics. Communication.
De la performance a la grabación: presupuestos del debate sobre la estética del Rock

\section{Resumen}

Partiendo de la revisión de teces representativas sobre una estética particular del Rock, el articulo problematiza los presupuestos sobre performance y/o grabación como objetos estéticos y sugiere dislocar el debate para el entendimiento sobre los elementos llamados en causa en la experiencia con el Rock, en distintos contextos. Como conclusión, presenta la posibilidad de identificación de padrones poéticos predominantes en la experiencia musical que pueden ser objetos de estudio de la comunicación.

\section{Palabras clave}

Rock. Estética. Comunicación. 


\section{Expediente}

A revista E-Compós é a publicação científica em formato eletrônico da Associação Nacional dos Programas de Pós-Graduação em Comunicação (Compós). Lançada em 2004, tem como principal finalidade difundir a produção acadêmica de pesquisadores da área de Comunicação, inseridos em instituições do Brasil e do exterior.

\section{E-COMPÓS I www.e-compos.org.br I E-ISSN 1808-2599}

Revista da Associação Nacional dos Programas de Pós-Graduação em Comunicação. Brasília, v.13, n.2, maio/ago. 2010.

A identificação das edições, a partir de 2008 passa a ser volume anual com três números.

\section{CONSELHO EDITORIAL}

Afonso Albuquerque

Universidade Federal Fluminense, Brasil

Alberto Carlos Augusto Klein

Universidade Estadual de Londrina, Brasil

Alex Fernando Teixeira Primo

Universidade Federal do Rio Grande do Sul, Brasil

Alfredo Vizeu

Universidade Federal de Pernambuco, Brasi

Ana Carolina Damboriarena Escosteguy

Pontifícia Universidade Católica do Rio Grande do Sul, Brasil

Ana Silvia Lopes Davi Médola

Universidade Estadual Paulista, Brasil

André Luiz Martins Lemos

Universidade Federal da Bahia, Brasil

Ângela Freire Prysthon

Universidade Federal de Pernambuco, Brasil

Antônio Fausto Neto

Universidade do Vale do Rio dos Sinos, Brasil

Antonio Carlos Hohlfeldt

Pontifícia Universidade Católica do Rio Grande do Sul, Brasil

Arlindo Ribeiro Machado

Universidade de São Paulo, Brasil

César Geraldo Guimarães

Universidade Federal de Minas Gerais, Brasil

Cristiane Freitas Gutfreind

Pontifícia Universidade Católica do Rio Grande do Sul, Brasil

Denilson Lopes

Universidade Federal do Rio de Janeiro, Brasil

Eduardo Peñuela Cañizal

Universidade Paulista, Brasi

Erick Felinto de Oliveira

Universidade do Estado do Rio de Janeiro, Brasil

Francisco Menezes Martins

Universidade Tuiuti do Paraná, Brasil

Gelson Santana

Universidade Anhembi/Morumbi, Brasil

Goiamérico Felício

Universidade Federal de Goiás, Brasil

Hector Ospina

Universidad de Manizales, Colômbia

Herom Vargas

Universidade Municipal de São Caetano do Sul, Brasil

leda Tucherman

Universidade Federal do Rio de Janeiro, Brasil

Itania Maria Mota Gomes

Universidade Federal da Bahia, Brasil

Janice Caiafa

Universidade Federal do Rio de Janeiro, Brasil

Jeder Silveira Janotti Junior

Universidade Federal da Bahia, Brasil

João Freire Filho

Universidade Federal do Rio de Janeiro, Brasil

John DH Downing

University of Texas at Austin, Estados Unidos

José Luiz Aidar Prado

Pontifícia Universidade Católica de São Paulo, Brasil

José Luiz Warren Jardim Gomes Braga

Universidade do Vale do Rio dos Sinos, Brasil

Juremir Machado da Silva

Pontifícia Universidade Católica do Rio Grande do Sul, Brasil

Lorraine Leu

University of Bristol, Grã-Bretanha

Luiz Claudio Martino

Universidade de Brasília, Brasil

Maria Immacolata Vassallo de Lopes

Universidade de São Paulo, Brasil

Maria Lucia Santaella

Pontifícia Universidade Católica de São Paulo, Brasil

Mauro Pereira Porto

Tulane University, Estados Unidos

Muniz Sodre de Araujo Cabral

Universidade Federal do Rio de Janeiro, Brasil

Nilda Aparecida Jacks

Universidade Federal do Rio Grande do Sul, Brasil

Paulo Roberto Gibaldi Vaz

Universidade Federal do Rio de Janeiro, Brasil

Renato Cordeiro Gomes

Pontifícia Universidade Católica do Rio de Janeiro, Brasil

Ronaldo George Helal

Universidade do Estado do Rio de Janeiro, Brasil

Rosana de Lima Soares

Universidade de São Paulo, Brasil

Rossana Reguillo

Instituto Tecnológico y de Estudios Superiores do Occidente, México

Rousiley Celi Moreira Maia

Universidade Federal de Minas Gerais, Brasil

Samuel Paiva

Universidade Federal de São Carlos, Brasil

Sebastião Albano

Universidade Federal do Rio Grande do Norte, Brasil

Sebastião Carlos de Morais Squirra

Universidade Metodista de São Paulo, Brasi

Simone Maria Andrade Pereira de Sá

Universidade Federal Fluminense, Brasil

Suzete Venturelli

Universidade de Brasília, Brasil

Valério Cruz Brittos

Universidade do Vale do Rio dos Sinos, Brasil

Veneza Mayora Ronsini

Universidade Federal de Santa Maria, Brasil

Vera Regina Veiga França

Universidade Federal de Minas Gerais, Brasi

\section{COMISSÃO EDITORIAL}

Felipe da Costa Trotta I Universidade Federal de Pernambuco, Brasil Rose Melo Rocha I Escola Superior de Propaganda e Marketing, Brasil Adriana Braga I Pontificia Universidade Católica do Rio de Janeiro, Brasil CONSULTORES AD HOC

Roseli Figaro I Universidade de São Paulo, Brasil

Miguel Serpa Pereira I Pontifícia Universidade Católica do Rio de Janeiro, Brasil João Maia I Universidade do Estado do Rio de Janeiro, Brasil

Paulo Cunha Filho I Universidade Federal de Pernambuco, Brasil Benjamim Picado I Universidade Federal Fluminense, Brasil Josimey Silva I Universidade Federal do Rio Grande do Norte, Brasil REVISÃO DE TEXTO E TRADUÇÃo I Everton Cardoso EDITORAÇÃo ELETRÔNICA I Roka Estúdio
COMPOS I wWw.compos.org.br

Associação Nacional dos Programas de Pós-Graduação em Comunicação

Presidente

Itania Maria Mota Gomes

Universidade Federal da Bahia, Brasil

itania@ufba.br

Vice-presidente

Julio Pinto

Pontifícia Universidade Católica de Minas Gerais, Brasil juliopinto@pucminas.br

Secretária-Geral

Ana Carolina Escosteguy

Pontifícia Universidade Católica do Rio Grande do Sul, Brasil carolad@pucrs.br 